\title{
Adjunctive Risperidone for Partially Responsive People with Schizophrenia Treated with Clozapine
}

\author{
Elaine Weiner', Robert R Conley², M Patricia Ball', Stephanie Feldman', James M Gold', Deanna L Kelly', \\ Ikwunga Wonodi', Robert P McMahon' and Robert W Buchanan*,' \\ 'Maryland Psychiatric Research Center, Department of Psychiatry, University of Maryland School of Medicine, Baltimore, MD, USA; ${ }^{2}$ Eli Lilly and \\ Company, Lilly Bio-Medicines, Neuroscience, Indianapolis, IN, USA
}

\begin{abstract}
The large numbers of partial clozapine responders represent a major therapeutic challenge. Unfortunately, there are no clear data to support how best to treat these patients. This study examines the efficacy and safety of adjunctive risperidone in a well-defined treatment-resistant population optimally treated with clozapine. A total of 69 inpatients and outpatients with DSM-IV schizophrenia or schizoaffective disorder entered a 16-week double-blind, placebo-controlled, randomized clinical trial. Of them, 33 participants were randomized to risperidone and 36 were randomized to placebo. There was no significant group difference in the predefined response criteria. There were modest group differences for Brief Psychiatric Rating Scale (BPRS) positive symptoms, which were significant in the completer analysis $(F=5.70 ; \mathrm{df}=1,70.3 ; p=0.02 ; E S=0.27)$ but not the intent-to-treat $(\mathrm{ITT})$ analyses $(F=3.01 ; \mathrm{df}=1,77.5 ; p=0.09$; $E S=0.19$ ). A similar pattern was found for the BPRS total score, with the completer analysis showing a significant improvement in the risperidone group $(F=5.21 ; d f=1,64.9 ; p=0.03 ; E S=0.27)$, whereas the $I T T$ analysis was not significant $(F=3.52 ; d f=1,71.3$; $p=0.06$; $E S=0.22$ ). In addition, there was a small, but significant, group difference for negative symptoms, as measured by the SANS total score, which favored the risperidone group $(F=5.67 ; \mathrm{df}=1,78.7 ; p=0.02 ; E S=0.24)$. There were no significant group differences on safety measures, including neuropsychological test and extrapyramidal symptom scores. A significant elevation of prolactin in the risperidone group was observed. The study results suggest that adjunctive risperidone may have a modest benefit for treatment-resistant clozapine patients. The study results are discussed in the context of previous double-blind studies of adjunctive risperidone. (clinicaltrials.gov, trial number: NCT00056498).

Neuropsychopharmacology (2010) 35, 2274-2283; doi: I0.1038/npp.20 I0.10 I; published online 2I July 2010
\end{abstract}

Keywords: schizophrenia; risperidone; clozapine; treatment resistant; positive symptoms; negative symptoms

\section{INTRODUCTION}

Clozapine is the only antipsychotic that has been found to show superior efficacy for treatment-resistant schizophrenia (Kane et al, 1988; Buchanan et al, 1998; Lewis et al, 2006; McEvoy et al, 2006). Unfortunately, $<50 \%$ of people prescribed clozapine will adequately respond, which leaves a substantial proportion with ongoing, often debilitating, positive symptoms (Buchanan et al, 1998; Rosenheck et al, 1998; Kane et al, 2001; McEvoy et al, 2006). These partial or poor clozapine responders represent a major therapeutic challenge and raise the question of how best to treat them. The major emerging treatment trend is to add a second

*Correspondence: Dr RW Buchanan, Maryland Psychiatric Research Center, Department of Psychiatry, University of Maryland School of Medicine, PO Box 21247, Baltimore, 21228 MD, USA, Tel: + 410402 7876, Fax: + 4104027198 ,

E-mail: rwbuchanan@mprc.umaryland.edu

Received 5 January 20 I0; revised 10 June 20 I0; accepted 16 June 2010 antipsychotic medication, with risperidone commonly used for this purpose, although there is little empirical evidence to support the efficacy of this approach.

The rationale for the use of adjunctive risperidone is based, in part, on the differential actions of risperidone and clozapine on the dopamine D2 receptor. Risperidone is a potent dopamine D2 receptor antagonist, with a comparable level of striatal D2 receptor binding as haloperidol (Kapur et al, 1996; Kapur et al, 1999). In contrast, clozapine has relatively low affinity for striatal D2 receptors and even at high doses occupies $<65 \%$ of these receptors (Kapur et al, 1999). In addition, D2 receptors regulate two intracellular signaling cascades, the $\mathrm{G}_{\mathrm{i} / \mathrm{o}}$ and $\beta$-arrestin 2 pathways, with the $\mathrm{G}_{\mathrm{i} / \mathrm{o}}$ pathway hypothesized to be critical for the efficacy of antipsychotics (Beaulieu et al, 2007; Masri et al, 2008). Risperidone shows potent antagonistic activity for both the $\mathrm{G}_{\mathrm{i} / \mathrm{o}}$ and $\beta$-arrestin 2 pathways, whereas the antagonistic activity of clozapine is limited to the $\beta$-arrestin 2 pathway (Beaulieu et al, 2007; Masri et al, 2008). 
There is also indirect evidence to support the utility of adjunctive risperidone. A series of studies have compared the differential effect of clozapine and haloperidol on immediate early gene induction, in which clozapine uniquely induces $\mathrm{c}$-fos, fos $\mathrm{B}$, and fra 2 gene expression in the prelimbic/prefrontal cortex, whereas haloperidol uniquely induces c-fos expression in the substantia nigra (Nguyen et al, 1992; MacGibbon et al, 1994; Cochran et al, 2002). Both drugs induce early genes in the caudate/ putamen and nucleus accumbens, but the specific genes vary across drug and anatomical site (Nguyen et al, 1992; MacGibbon et al, 1994; Cochran et al, 2002). The two drugs also produce a differential pattern of regional cerebral blood flow (rCBF) activation, with clozapine producing a greater $\mathrm{rCBF}$ increase in the anterior cingulate and dorsolateral prefrontal cortex, and haloperidol producing a greater $\mathrm{rCBF}$ increase in the dorsal and ventral striatum (Lahti et al, 2003). In combination, these studies suggest that clozapine and haloperidol may exert their therapeutic actions through different brain regions or neural circuits. If risperidone shares some of these actions with haloperidol, through the shared mechanism of potent $\mathrm{D} 2$ receptor antagonism, then risperidone could exert differential and possibly complementary effects to clozapine on the various brain regions implicated in antipsychotic efficacy (Holcomb et al, 1996; Lahti et al, 2003).

Four previous studies have examined the use of adjunctive risperidone in partial or poor clozapine responders (Josiassen et al, 2005; Anil Yağcioğlu et al, 2005; Honer et al, 2006; Freudenreich et al, 2007). Two studies found significant benefits of adjunctive risperidone for either total psychopathology or positive symptoms (Josiassen et al, 2005; Freudenreich et al, 2007), whereas the other studies failed to find any significant differences (Anil Yağcioğlu et al, 2005; Honer et al, 2006). Adjunctive risperidone has also been shown to worsen some measures of cognition (Honer et al, 2006; Kivircik Akdede et al, 2006) and to cause significant elevations in prolactin (Anil Yağcioğlu et al, 2005; Freudenreich et al, 2007) and blood glucose (Honer et al, 2006). In light of the contrasting efficacy results and potential adverse effects, it remains unclear whether this augmentation strategy is of sufficient clinical benefit to warrant the risk of increased adverse events. The current randomized clinical trial was designed to examine the efficacy and safety of adjunctive risperidone for the treatment of positive symptoms, with the secondary aim to examine the effect of this combination on cognition, metabolic and motor side effects, and negative symptoms.

\section{PARTICIPANTS AND METHODS}

Inpatients or outpatients, between 18 and 65 years, who met DSM-IV criteria for schizophrenia or schizoaffective disorder were selected for study entry. Participants were diagnosed using a best estimate diagnostic approach that used information from the Structured Clinical Interview for DSM-IV (First et al, 1997), direct assessment, family informants, and past medical records. Participants were judged by their primary treating clinician to be clinically stable, in the nonacute phase of their illness. They met the following treatment-resistance criteria: (1) Brief Psychiatric
Rating Scale (BPRS; Overall and Gorham, 1962) total score of $\geqslant 45$ or Clinical Global Impression (CGI) severity of illness item score of $\geqslant 4$; and (2) BPRS positive symptom item total score of $\geqslant 8$, with one or more item rated $\geqslant 4$. They were required to have had an adequate clozapine trial, defined as clozapine treatment for $\geqslant 6$ months on a dose that produced a clozapine plasma level of $\geqslant 350 \mathrm{ng} / \mathrm{ml}$ or a clozapine + norclozapine plasma level of $\geqslant 450 \mathrm{ng} / \mathrm{ml}$ (Perry et al, 1991; Kronig et al, 1995). Participants who met DSMIV diagnosis of alcohol or substance abuse (other than nicotine) within the past month, alcohol or substance dependence (other than nicotine) within the past 6 months, or mental retardation, or had an unstable medical condition, were excluded. Participants treated previously with adjunctive risperidone at $\geqslant 8 \mathrm{mg} /$ day for at least 6 weeks were excluded.

The IRB of the University of Maryland School of Medicine approved the study protocol and informed consent procedures. Written informed consent was obtained from all participants after study procedures had been fully explained and before study participation. The ability of the participants to provide valid informed consent was documented using study-specific procedures.

\section{Clinical Assessments}

The BPRS positive symptom item total score was used to assess positive symptom change. The four BPRS positive symptom items are: conceptual disorganization, hallucinatory behavior, unusual thought content, and suspiciousness. The BPRS anxiety/depression factor was used to assess affective symptom change. The modified Scale for the Assessment of Negative Symptoms (SANS; Buchanan et al, 2007) total score was used to assess negative symptom change. The CGI severity of illness item was used to assess global changes. The Level of Functioning scale (LOF; Hawk et al, 1975) was used to assess social and occupational functioning.

The BPRS, SANS, and CGI were obtained at the evaluation phase weeks 0 and 4 and biweekly during the 16-week double-blind treatment phase. The LOF was obtained at evaluation phase week 4 and double-blind treatment phase week 16. Intraclass correlation coefficients for these instruments ranged from 0.76 to 0.90 . All raters were blind to treatment assignment.

The Drug Attitude Inventory (DAI; Awad, 1993) is a selfreport scale designed to assess subjective response to antipsychotic treatment. Each item is scored true/false. The DAI was obtained at double-blind treatment phase week 16 .

\section{Neuropsychological Assessments}

Participants were administered a neuropsychological test battery at evaluation phase week 4 and at double-blind treatment phase week 16 . The battery included the following tests: attention: 2,3,4 Continuous Performance Test (Cornblatt and Keilp, 1994); executive function: Trails Making Test A and B (Reitan, 1958) and Wisconsin Card Sorting Test (Heaton et al, 1993); motor speed: Grooved Pegboard (Matthews and Klove, 1964); processing speed: WAIS-III Digit Symbol Test; response generation: Category Fluency 
Test (Lezak, 2004) and Controlled Oral Word Association (Benton and Hamsher, 1989); verbal memory: Hopkins Verbal Learning Test (HVLT; Brandt, 1991); visual memory: Brief Visuospatial Memory Test-Revised (BVMT; Benedict, 1997); working memory: Hershey Visuospatial Working Memory (Hershey et al, 1998) and WAIS-III Letter-Number Sequencing (LNS; Gold et al, 1997). Alternate forms of the HVLT and BVMT were used for the two test occasions.

\section{Safety Assessments}

The Simpson Angus Scale (SAS; Simpson and Angus, 1970), the Abnormal Involuntary Movement Scale (AIMS; Guy, 1976), and the Barnes Akathisia Scale (BAS; Barnes, 1989) were used to assess extrapyramidal symptoms (EPS), dyskinetic movements, and akathisia, respectively. The SAS, AIMS, and BAS were administered at evaluation phase week 4 and biweekly during the 16-week double-blind treatment phase.

A standard chemistry panel, complete blood count, urinalysis, and EKG were obtained at evaluation phase week 0 and at double-blind treatment phase week 16. The Side-Effect Checklist (SEC) was used to assess side effects and monitor vital signs. Height was measured using a wallmounted stadiometer. Weight was measured on a digital scale after participants had removed shoes, outerwear, and pocket contents. The SEC comprises 22 common side effects, which are rated on a 1 (none) to 4 (severe) scale. The SEC ratings were conducted at evaluation phase week 4 and biweekly during the 16-week double-blind treatment phase by a nonblind pharmacist. Clozapine blood levels and prolactin levels were obtained at evaluation phase week 4 and at double-blind treatment phase week 16 .

\section{Study Design}

Participants who met inclusion criteria entered the 4-week evaluation phase during which they underwent medical screening and baseline symptom, safety, and cognitive assessments. Participants who continued to meet inclusion criteria entered the 16-week double-blind treatment phase and were randomized to risperidone $4 \mathrm{mg}$ (two $2 \mathrm{mg}$ capsules) or placebo (two capsules). The risperidone $4 \mathrm{mg}$ dose was chosen to balance the need for increased dopamine blockade while minimizing EPS associated with excessive dopamine blockade. Randomization was stratified by in-patient status. If a participant could not tolerate their study medication, they were instructed to skip a dose and were then re-challenged with the prescribed dose. If the participant was still unable to tolerate their study medication, then the dose could be lowered by $1 \mathrm{mg}$ increments to alleviate side effects. All participants were maintained on their baseline clozapine dose. Clozapine dosage adjustments were not allowed during the course of the study.

Medication compliance was assessed by weekly pill count. All participants who received $\geqslant 75 \%$ of their assigned study medication were considered compliant.

\section{Statistical Analyses}

Positive symptom improvement was examined through a responder analysis and change in BPRS positive symptom item total score. In the preplanned primary analysis, repeated measures logistic regression was to be used to compare the probability of being in a state of response in the two groups (Liang and Zeger, 1986). Treatment response was defined a priori as a $\geqslant 20 \%$ reduction in the BPRS positive symptom total score and a BPRS positive symptom item total score $<8$ on one or more of the last four biweekly ratings.

Intent-to-treat (ITT) and completer analyses were used to examine change in BPRS positive symptom item total score. The ITT analysis approximates treatment effectiveness in actual clinical care situations, but is vulnerable to early terminations, and may underestimate treatment efficacy (Feinman, 2009). The completer analysis approximates treatment efficacy, but may be vulnerable to optimistic bias because of dropout of participants with clinical worsening. The use of both approaches provides an estimate of treatment effectiveness, including adherence with the experimental treatment, and optimal efficacy of the experimental treatment (Feinman, 2009). The ITT analysis included all participants who received at least one dose of study medication. The completer analysis included all participants who completed the double-blind phase.

The ITT and completer analyses used a mixed model for unbalanced repeated measures analysis of covariance (ANCOVA), in which follow-up symptom score = baseline symptom score + treatment + week + treatment $\times$ week, and week is treated as a categorical rather than a continuous measure. The treatment term estimates the average across weeks of the week-specific group differences, and is used as the main test for treatment effects on symptom change; the treatment $\times$ week interaction term is used to explore whether treatment differences vary significantly across week, without pre-supposing a particular pattern (eg, linear) for trends in treatment effect. This choice of analysis was based on the observation that models assuming linear time trends misfit the data and can have dramatically reduced power compared with mixed model estimates of the average of the week-specific differences (McMahon et al, 2008). Mixed models were fitted using SAS PROC MIXED. Effect sizes for treatment difference were estimated by $d=$ (mixed model estimate of treatment main effect)/ (pooled SD of follow-up scores), where the pooled SD was estimated from the square root of the sum of the withinand between-subject variance components of the score. The same analytic approach was used for BPRS total and anxiety/depression scores and the SANS total score.

The Wilcoxon rank-sum test was used to assess treatment differences in neuropsychological test performance. The individual test raw scores were converted to $z$-scores and an overall composite $z$-score was computed from the average of the individual test $z$-scores. An adaptation of the Pepe, Whitaker, and Seidel method was used to test for heterogeneity of effect across neuropsychological tests (Pepe et al, 1999). Exploratory analyses of individual neuropsychological test treatment differences were performed. The Benjamini and Hochberg procedure was used to control the false discovery rate (Benjamini and Hochberg, 1995). The LOF items were examined using the Mantel-Haenszel (Mantel, 1963) $\chi^{2}$ test. Longitudinal trends in repeated CGI, SAS, AIMS, and BAS assessments were compared using the Conover-Salsburg rank test (Conover 
and Salsburg, 1988; McMahon et al, 2005). For each SEC item, Fisher's exact test was used to compare treatments on the number of participants who, at any point during followup, had new or worsened (compared with baseline) sideeffect severity. ANCOVA was used to examine mean changes in laboratory measures and vital signs. The Wilcoxon rank-sum test was used to compare DAI total scores.

\section{RESULTS}

The participant flow is presented in Figure 1. In all, 69 subjects were randomized: 33 were randomized to risperidone (25 outpatients and 8 inpatients) and 36 were randomized to placebo (26 outpatients and 10 inpatients).
Four participants withdrew before receiving study medication: 3 risperidone participants and one placebo participant. A total of 65 participants entered the double-blind phase of the study: 30 were randomized to risperidone (23 outpatients and 7 inpatients) and 35 to placebo (24 outpatients and 10 inpatients). In all, 53 participants completed the study. The demographic and baseline clinical characteristics of the 64 participants included in analyses are presented in Table 1. Age was the only demographic or clinical characteristic to significantly differ between the groups, with the risperidone group being older than the placebo group.

The baseline clozapine and clozapine + norclozapine levels are presented in Table 1. The end of study (EOS) clozapine levels were: risperidone $(n=25) 564.9 \pm 364.7 \mathrm{ng} / \mathrm{ml}$; placebo $(n=32) \quad 641.1 \pm 373.6 \mathrm{ng} / \mathrm{ml} ; \quad\left(\chi^{2}=4.87 ; \quad \mathrm{df}=1\right.$;

Ineligible/Excluded: 15

6: withdrew consent due to changing their minds

1: withdrew consent by declining medical workup

2: withdrew consent by declining medication

changes associated with the study

5: had BPRS positive symptoms below the

inclusion criterion

1: did not meet inclusion criteria (not further specified)

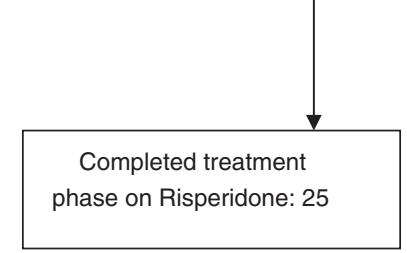

Discontinued treatment: 8 ( 1 did not receive study medication)

1: wk 0 clinical worsening

1: wk 1 chose to discontinue

1: wk 4 clinical worsening

1: wk 8 med noncompliance

1: wk 9 clinical worsening

1: wk 12 moved from area

1: wk 12 clinical worsening

1: wk 12 abnormal labs

Figure I Participant flow through study. 
$p=0.03)$ and the EOS clozapine + norclozapine levels were: risperidone $(n=25) 810.3 \pm 464.2 \mathrm{ng} / \mathrm{ml}$; placebo $(n=32)$ $950.2 \pm 499.3 \mathrm{ng} / \mathrm{ml}$. There were no significant group differences in change in clozapine $\left(\chi^{2}=0.67 ; \mathrm{df}=1\right.$; $p=0.41) \quad$ or clozapine + norclozapine levels $\quad\left(\chi^{2}=0.70\right.$; $\mathrm{df}=1 ; p=0.40)$. The EOS risperidone dose was $3.96 \pm 0.20 \mathrm{mg} /$ day.

\section{Symptom Measures}

Four participants from each treatment group met the predefined positive symptom response criteria: two risper-

Table I Demographic and Baseline Clinical Characteristics

\begin{tabular}{|c|c|c|c|}
\hline & $\begin{array}{c}\text { Risperidone } \\
\text { mean ( } \pm \text { SD) }\end{array}$ & $\begin{array}{c}\text { Placebo } \\
\text { mean }( \pm S D)\end{array}$ & p-value \\
\hline N & 30 & 34 & \\
\hline Age (years) & $48.3(7.2)$ & $44.1(9.3)$ & 0.04 \\
\hline Gender ( $N$; \% male) & $19 ; 63.3 \%$ & $25 ; 73.5 \%$ & 0.38 \\
\hline Race $(N$; white $)$ & $23 ; 76.7 \%$ & $22 ; 64.7 \%$ & 0.30 \\
\hline Diagnosis ( $\mathrm{N}$; \% schizophrenia) & $27 ; 90 \%$ & $30 ; 88.2 \%$ & 0.82 \\
\hline Age of onset (years) & $20.5(7.5)$ & $18.2(5.5)$ & 0.16 \\
\hline Body mass index (BMl, in $\left.\mathrm{kg} / \mathrm{m}^{2}\right)$ & $30.3(6.4)$ & $32.4(6.1)$ & 0.19 \\
\hline $\mathrm{BMI}<25(\mathrm{~N} ; \%)$ & $7(24.1)$ & $2(6.1)$ & \\
\hline $\mathrm{BMI} \geqslant 25$ but $<30(\mathrm{~N} ; \%)$ & $3(10.3)$ & $4(12.1)$ & \\
\hline $\mathrm{BMI} \geqslant 30(\mathrm{~N} ; \%)$ & $19(65.5)$ & $27(81.1)$ & \\
\hline BPRS total score & $43.0(8.7)$ & $44.4(9.2)$ & 0.53 \\
\hline BPRS positive symptom item score & $15.5(3.8)$ & $15.5(3.8)$ & 0.96 \\
\hline BPRS anxiety/depression & $9.6(3.5)$ & $10.0(4.2)$ & 0.71 \\
\hline SANS total score & $30.4(11.0)$ & $31.2(12.5)$ & 0.79 \\
\hline CGI severity of illness & $4.7(0.7)$ & $4.9(0.7)$ & 0.16 \\
\hline Clozapine level (ng/ml) & $680.1 \pm 446.6$ & $491.2 \pm 264.0$ & 0.06 \\
\hline Clozapine+norclozapine level $(\mathrm{ng} / \mathrm{ml})$ & $742.3 \pm 398.7$ & $1031.8 \pm 645.0$ & 0.03 \\
\hline
\end{tabular}

idone participants met response criteria twice during the final four visits, and one placebo participant met the criteria three times during the final four visits. The number of responders was too few to perform further analysis.

BPRS positive symptom item total score. The ITT and completer analyses produced similar results. In the ITT analysis, there was a numerical, but not statistically significant, group difference $(\mathrm{F}=3.01 ; \mathrm{df}=1,77.5$; $p=0.09$ ), with risperidone participants showing a greater decrease in BPRS positive symptom items (see Table 2). In the completer analysis, the risperidone group had a significantly greater positive symptom decrease than the placebo group $(\mathrm{F}=5.70 ; \mathrm{df}=1,70.3 ; p=0.02)$. The effect size for the ITT analysis was 0.19 and for the completer analysis was 0.27 .

In light of the trend for significant group differences in both baseline clozapine and clozapine + norclozapine levels, the correlations between baseline clozapine and clozapine + norclozapine levels and change in BPRS positive symptom item total score and between change in clozapine and clozapine + norclozapine levels and change in BPRS positive symptom item total score were examined. There were no significant correlations with the clozapine measures (Spearman's $R=0.19, p=0.21$; and Spearman's $R=-0.13$, $p=0.41$, respectively) or the clozapine + norclozapine measures (Spearman's $R=0.19, p=0.20$; and Spearman's $R=-0.12, p=0.42$, respectively).

The treatment group by week interaction was not significant for either the ITT $(\mathrm{F}=0.73 ; \mathrm{df}=7,376.5$; $p=0.65)$ or completer $(\mathrm{F}=1.54 ; \mathrm{df}=7,345.3 ; p=0.15)$ analyses, which suggests that there was no significant difference in the temporal pattern of symptom change between the two groups.

BPRS total score. The same result pattern was observed for the BPRS total score (see Table 2). In the ITT analysis, there was a numerical, but not statistically significant, group difference $(\mathrm{F}=3.52 ; \mathrm{df}=1,71.3 ; p=0.06)$, with risperidone

Table 2 BPRS Scores by Week and Treatment Group

\begin{tabular}{|c|c|c|c|c|c|c|c|c|}
\hline \multirow{2}{*}{ Week } & \multicolumn{4}{|c|}{ Risperidone mean ( \pm SD) } & \multicolumn{4}{|c|}{ Placebo mean $( \pm \mathrm{SD})$} \\
\hline & $\mathbf{N}$ & $\begin{array}{l}\text { Total } \\
\text { score }\end{array}$ & $\begin{array}{l}\text { Positive symptom } \\
\text { item score }\end{array}$ & $\begin{array}{l}\text { Anx./depr. } \\
\text { factor }\end{array}$ & $\mathbf{N}$ & $\begin{array}{l}\text { Total } \\
\text { score }\end{array}$ & $\begin{array}{l}\text { Positive symptom } \\
\text { item score }\end{array}$ & $\begin{array}{l}\text { Anx./depr. } \\
\text { factor }\end{array}$ \\
\hline 0 & 30 & $43.0 \pm 8.7$ & $15.5 \pm 3.8$ & $9.6 \pm 3.5$ & 34 & $44.4 \pm 9.2$ & $15.5 \pm 4.2$ & $10.0 \pm 4.2$ \\
\hline 2 & 30 & $40.1 \pm 8.9$ & $14.6 \pm 3.7$ & $8.9 \pm 3.7$ & 34 & $42.8 \pm 9.6$ & $|5| \pm 4.0$. & $9.4 \pm 4.0$ \\
\hline 8 & 28 & $38.6 \pm 10.0$ & $13.5 \pm 4.2$ & $8.8 \pm 3.8$ & 33 & $41.9 \pm 10.2$ & $14.9 \pm 3.9$ & $8.9 \pm 3.9$ \\
\hline 10 & 26 & $37.5 \pm 9.3$ & $13.9 \pm 4.2$ & $7.4 \pm 3.1$ & 31 & $42.3 \pm 10.4$ & $14.9 \pm 4.2$ & $8.8 \pm 4.2$ \\
\hline 12 & 25 & $37.8 \pm 8.7$ & $13.8 \pm 3.7$ & $7.7 \pm 3.1$ & 31 & $42.7 \pm 10.4$ & $15.3 \pm 4.6$ & $9.3 \pm 4.6$ \\
\hline 14 & 24 & $37.0 \pm 8.7$ & $13.4 \pm 3.5$ & $7.3 \pm 3.3$ & 28 & $41.1 \pm 10.6$ & $14.2 \pm 3.8$ & $8.4 \pm 3.8$ \\
\hline 16 & 25 & $36.4 \pm 9.3$ & $13.2 \pm 3.5$ & $7.6 \pm 3.1$ & 28 & $41.0 \pm 10.3$ & $\mid 4.1 \pm 3.6$ & $8.6 \pm 3.6$ \\
\hline
\end{tabular}

Intention-to-treat estimates for risperidone-placebo differences \pm SE (averaged across all follow-up weeks) adjusted for baseline score using mixed model ANCOVA were: BPRS total score, $-2.2 \pm 1 . \mathrm{I}(\mathrm{F}=3.6 \mathrm{I} ; \mathrm{df}=1,7 \mathrm{I} .9 ; p=0.06 \mathrm{I})$; BPRS positive symptom item score, $-0.8 \pm 0.5(\mathrm{~F}=3.0 \mathrm{l} ; \mathrm{df}=1,77.5 ; p=0.087) ; \mathrm{BPRS}$ anxiety depression score, $-0.4 \pm 0.4(F=0.73 ; d f=1,76.8 ; p=0.40)$. 
Table 3 SANS Total Score by Week and Treatment Group

\begin{tabular}{|c|c|c|c|c|}
\hline \multirow{2}{*}{ Week } & \multicolumn{2}{|c|}{ Risperidone } & \multicolumn{2}{|c|}{ Placebo } \\
\hline & $N$ & Mean \pm SD & $N$ & Mean \pm SD \\
\hline 0 & 30 & $32.3 \pm 11.6$ & 34 & $33.0 \pm 13.3$ \\
\hline 2 & 30 & $30.8 \pm 11.5$ & 34 & $34.0 \pm 12.1$ \\
\hline 4 & 28 & $29.8 \pm 11.6$ & 34 & $32.9 \pm 13.3$ \\
\hline 6 & 28 & $31.2 \pm 10.3$ & 33 & $33.0 \pm 12.7$ \\
\hline 8 & 27 & $30.4 \pm 11.3$ & 33 & $34.0 \pm 14.1$ \\
\hline 10 & 25 & $30.6 \pm 10.9$ & 31 & $33.1 \pm 13.3$ \\
\hline 12 & 25 & $31.6 \pm 10.7$ & 31 & $32.4 \pm 12.5$ \\
\hline 14 & 24 & $31.7 \pm 11.0$ & 28 & $34.4 \pm 14.1$ \\
\hline 16 & 25 & $31.3 \pm 11.9$ & 28 & $34.4 \pm 14.8$ \\
\hline Change score & & $-2.6 \pm 5.6$ & & $1.1 \pm 10.8$ \\
\hline
\end{tabular}

Intention-to-treat estimates for risperidone-placebo SANS total score differences \pm SE (averaged across all follow-up weeks) adjusted for baseline score using mixed model ANCOVA were $-2.9 \pm 1.2(F=5.67 ; \mathrm{df}=1,78.7$; $p=0.029$ )

participants showing a greater decrease in global psychopathology. In the completer analysis, the comparison was significant with the risperidone group showing a greater decrease than the placebo group $(\mathrm{F}=5.21 ; \mathrm{df}=1,64.9$; $p=0.03)$. The effect size for the ITT analysis was 0.22 and for the completer analysis was 0.27 .

The treatment group by week interaction was not significant for either the ITT $(\mathrm{F}=0.39$; $\mathrm{df}=7,375.3$; $p=0.91)$ or completer $(\mathrm{F}=0.41 ; \mathrm{df}=7,345.3 ; p=0.90)$ analyses.

Other symptom measures. There was a significant group difference in SANS total scores $(\mathrm{F}=5.67 ; \mathrm{df}=1,78.7$; $p=0.02$; effect size $=0.24)$; this difference reflected a small decrease in the risperidone group and a small increase among placebo participants (see Table 3). The treatment group by week interaction was not significant $(\mathrm{F}=0.81$; $\mathrm{df}=7,382 ; p=0.58)$. The individual SANS subscale scores showed the same pattern of group differences, that is, slight improvement with risperidone and modest worsening with placebo, with only the group difference for the SANS anhedonia subscale statistically significant $\quad(\mathrm{F}=4.27$; $\mathrm{df}=1,88.6 ; p=0.04)$.

There were no significant group differences on the BPRS Anxiety/Depression factor score $(\mathrm{F}=0.73$; $\mathrm{df}=1,76.8$; $p=0.40$; see Table 2 ) or the CGI score (week 0: risperidone $(n=30) \quad 4.7 \pm 0.7$; placebo $(n=34) \quad 4.9 \pm 0.7$; week 16 : risperidone $(n=25) 4.5 \pm 0.8$; placebo $(n=28) 4.9 \pm 0.8$; $\mathrm{F}=0.17, \mathrm{df}=1.62, p=0.68)$. There were no significant group differences in the LOF overall level of function item $\left(\chi^{2}=0.09 ; \mathrm{df}=1 ; p=0.77\right)$ or other LOF items (data available upon request from the authors).

There were no group differences in the subjective responses to treatment: DAI total score: risperidone group $16.8 \pm 10.7$; placebo group $12.9 \pm 15.1 ; \chi^{2}=0.62, \mathrm{df}=1, p=0.43$.

\section{Neuropsychological Measures}

There were no significant group differences in the overall composite $z$-score $\left(\chi^{2}=0.86 ; \mathrm{df}=1 ; p=0.36\right)$; nor was there significant evidence of heterogeneity of treatment effects among tests $\left(\chi^{2}=11.0 ; \mathrm{df}=12 ; p=0.53\right.$; see Table 4$)$. None of the individual test score comparisons were statistically significant.

\section{Safety Measures}

The two groups did not significantly differ on the AIMS (risperidone: week $0(n=30) 3.5 \pm 5.5$ and week $16(n=25)$ $3.5 \pm 5.5$, change $0.1 \pm 2.3$; placebo: week $0(n=34) 2.0 \pm 2.7$ and placebo week $16(n=28) 2.2 \pm 2.8$, change $0.0 \pm 2.4$; $\mathrm{F}=0.05 ; \mathrm{df}=1,62 ; p=0.83$ ), the SAS (risperidone: week 0 $(n=30) 1.9 \pm 2.7$ and week $16(n=25) 1.8 \pm 3.4$, change $0.3 \pm 1.9$; placebo week $0(n=34) 1.4 \pm 1.9$ and week 16 $(n=28) \quad 1.8 \pm 2.5$, change $0.4 \pm 2.1 ; \mathrm{F}=0.04 ; \mathrm{df}=1,62$; $p=0.84)$, or the BAS (risperidone: week $0 \quad(n=30)$ $1.4 \pm 2.5$ and week $16(n=25) 0.7 \pm 1.6$, change $-0.7 \pm 2.2$; placebo: week $0(n=34) 1.0 \pm 2.5$ and week $16(n=28)$ $0.9 \pm 2.1 ; \mathrm{F}=1.02$, change $0.0 \pm 2.4$, change $-0.4 \pm 2.0$; $\mathrm{df}=1,62 ; p=0.32)$ total scores.

On the SEC, the only significant group difference was worsening of hypersalivation in the placebo group $(p=0.02)$. There was no significant group difference in fasting glucose (risperidone: week $0(n=20) 99.8 \pm 14.0 \mathrm{mg} / \mathrm{dl}$ and week $16(n=21) 96.6 \pm 23.5 \mathrm{mg} / \mathrm{dl}$, change $-1.7 \pm 26.7$; placebo group: week $0(n=24) 94.4 \pm 12.4 \mathrm{mg} / \mathrm{dl}$ and week $16(n=19) 101.2 \pm 16.5 \mathrm{mg} / \mathrm{dl}$, change $5.5 \pm 15.2 ; \chi^{2}=2.11$, $\mathrm{df}=1, p=0.15)$. There was a significant group difference in prolactin level (risperidone: week $0(n=20) 9.2 \pm 9.6 \mathrm{ng} / \mathrm{ml}$ and week $16(n=20) 41.7 \pm 37.4 \mathrm{ng} / \mathrm{ml}$, change $32.5 \pm 30.5 \mathrm{ng} /$ $\mathrm{ml}$; placebo: week $0(n=24) 7.0 \pm 3.4 \mathrm{ng} / \mathrm{ml}$ and week 16 $(n=24) 7.6 \pm 3.9 \mathrm{ng} / \mathrm{ml}$, change $0.5 \pm 2.7 \mathrm{ng} / \mathrm{ml} ; \chi^{2}=31.20$, $\mathrm{df}=1, \quad p<0.001)$. The most pronounced change was observed in the female participants (risperidone: week 0 $(n=7) \quad 15.9 \pm 14.1 \mathrm{ng} / \mathrm{ml}$ and week $16,70.7 \pm 49.2 \mathrm{ng} / \mathrm{ml}$; placebo: week $0(n=5) 8.1 \pm 4.7 \mathrm{ng} / \mathrm{ml}$ and week 16 , $\left.11.0 \pm 5.4 \mathrm{ng} / \mathrm{ml} ; \chi^{2}=8.08, \mathrm{df}=1, p=0.004\right)$, although there was also a significant group effect in the male participants (risperidone: week $0(n=13) 5.6 \pm 2.4 \mathrm{ng} / \mathrm{ml}$ and week 16 , $26.1 \pm 15.9 \mathrm{ng} / \mathrm{ml}$; placebo: week $0(n=19): 6.7 \pm 3.0 \mathrm{ng} / \mathrm{ml}$ and week 16,6.6 $\left.\pm 2.9 \mathrm{ng} / \mathrm{ml} ; \chi^{2}=22.45, \mathrm{df}=1, p<0.001\right)$. There was no significant difference in weight gain (risperidone: week $0(n=30) 87.9 \pm 14.5 \mathrm{~kg}$ and week 16 $(n=24) 88.8 \pm 15.0 \mathrm{~kg}$, change $0.1 \pm 2.9 \mathrm{~kg}$; placebo: week 0 $(n=34) 99.1 \pm 17.2 \mathrm{~kg}$ and week $16(n=26) 97.3 \pm 15.5 \mathrm{~kg}$, change $1.1 \pm 4.4 \mathrm{~kg} ; \mathrm{F}=2.25, \mathrm{df}=1,97, p=0.14)$. Among the participants who completed the study, none of the risperidone participants $(0 / 24)$ gained $\geqslant 7 \%$ of their baseline weight and only 2 of 24 placebo participants (8\%) gained $\geqslant 7 \%$ of their baseline weight. There were no significant differences in vital signs (data available upon request from the authors).

\section{DISCUSSION}

The study results suggest that adjunctive risperidone has a modest benefit for people with treatment-resistant schizophrenia who have failed to adequately respond to clozapine. There were no significant group differences in the small number of responders, but participants randomized to risperidone had a greater reduction in BPRS positive 
Table 4 Neuropsychological Test Results by Treatment and Visit

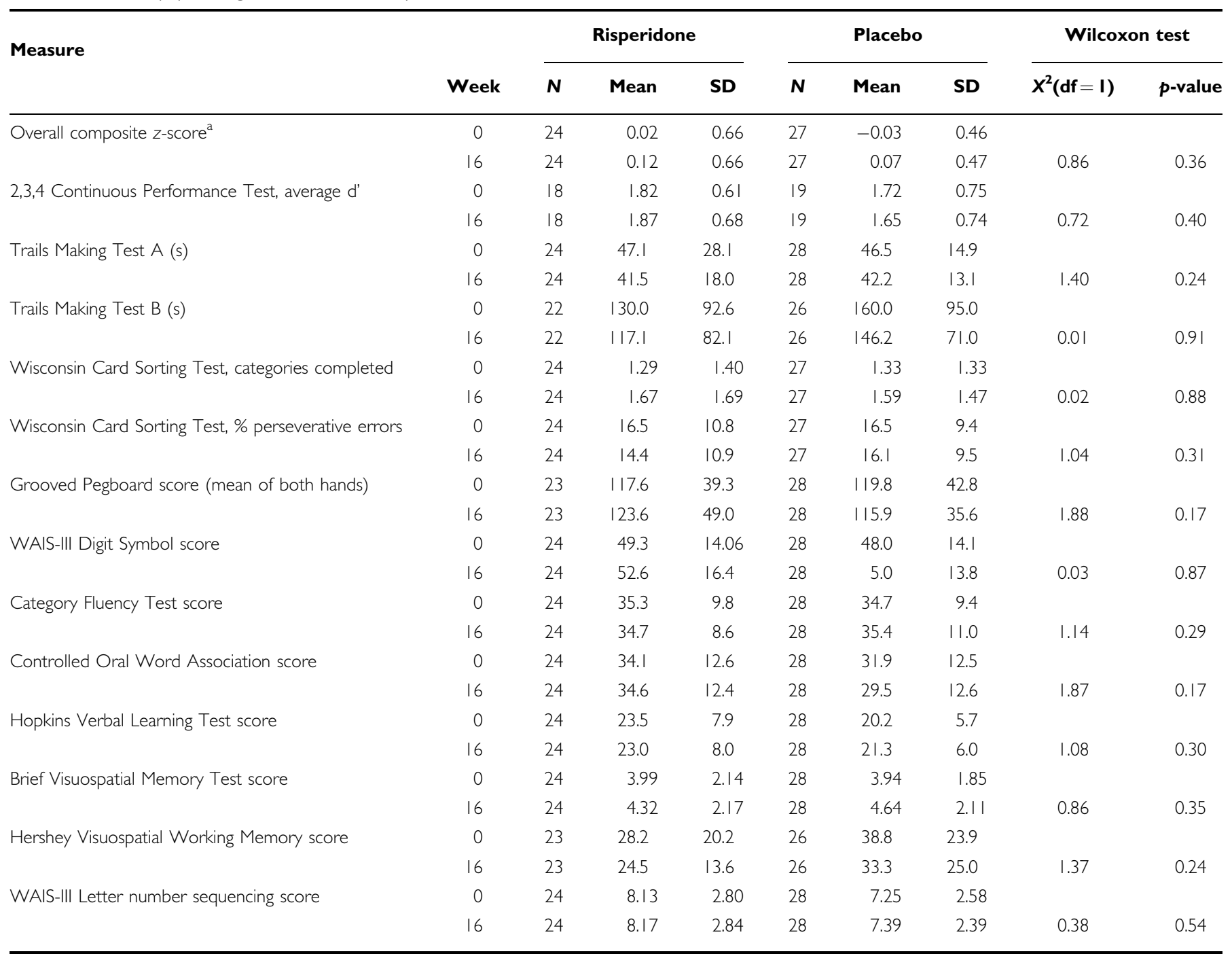

${ }^{a}$ Two participants completed $\leqslant 9$ of the 13 individual tests in the neurocognitive battery, and were omitted from calculation of the overall composite score, although their test results were used in secondary analysis of individual scores.

symptoms and BPRS total score. The effect sizes for group differences on these measures were modest and similar in both the ITT (ES $=0.18$ and 0.22 , respectively) and the completer analyses $(\mathrm{ES}=0.27$ for both scores), although group differences were statistically significant in the completer analyses $(p=0.03$ and $p=0.02$, respectively). The minor differences between the ITT and completer analyses may reflect the additional benefit accrued from extended exposure to risperidone. In the only other study that lasted $>8$ weeks, Josiassen et al (2005) also found a significant benefit for BPRS positive symptoms and BPRS total score.

There was a significant group difference for SANS total score: participants randomized to risperidone had a small decrease in negative symptoms, whereas the placebo group had a small increase of similar magnitude. Although the group difference is probably not of clinical significance, as the effect size was small, it is reassuring that the increased dopamine blockade of risperidone did not worsen negative symptoms. Josiassen et al (2005) and Freudenreich et al (2007) also observed the same pattern of negative symptom change, that is, negative symptom improvement in the risperidone group and a worsening of negative symptoms in the placebo group. The group difference was significant in the former study, but not in the latter study.

The lack of adverse effects associated with increased dopamine blockade was also reflected in the absence of any group differences in objective or self-report measures of EPS. Along the same lines, it is reassuring to note that risperidone was not associated with worsening of neuropsychological test performance, including those measures that assess fluency and possessing speed, in which, again, one might have expected a worsening because of the increase in dopamine blockade. Parenthetically, the lack of adverse effects of adjunctive risperidone on neuropsychological test performance is in contradistinction to previous studies in which negative effects were observed (Honer et al, 2006; Kivircik Akdede et al, 2006).

In general, adjunctive risperidone was well tolerated. Only two participants randomized to risperidone discontinued early from the study because of side effects. Moreover, as reflected in the mean EOS dose, the vast majority of 
participants were able to tolerate the $4 \mathrm{mg}$ target dose. Adjunctive risperidone was associated with increased prolactin levels, although there were no group differences in spontaneous reports of amenorrhea, galactorrhea, or sexual side effects. There were no group differences in fasting glucose or weight gain. Participants randomized to placebo were more likely to report a worsening of hypersalivation. Otherwise, there were no other significant group differences on the side-effect checklist.

The current study results must be considered in the context of previous double-blind studies of adjunctive risperidone. In a 12-week study, in which the mean risperidone dose was approximately $4 \mathrm{mg} /$ day, Josiassen et al (2005) found that risperidone had a significant beneficial effect for BPRS total and positive symptom scores and SANS total score. In addition, 35\% of risperidonetreated participants met treatment response criteria (ie, $\geqslant 20 \%$ reduction in BPRS total score) compared with $10 \%$ of those treated with placebo. Interestingly, all participants completed the study. The three other adjunctive risperidone studies were of shorter duration and failed to show a beneficial risperidone effect for the primary positive symptom measure or global psychopathology (Anil Yağcioğlu et al, 2005; Honer et al, 2006; Freudenreich et al, 2007). The studies of Anil Yağcioğlu et al (2005) and Freudenreich et al (2007) were both for 6 weeks and the Honer et al (2006) study was 8 weeks in duration. In two different meta-analyses analyses of combination antipsychotics vs monotherapy, study duration significantly predicted treatment outcome (Paton et al, 2007; Correll et al, 2009). In the first study, duration actually accounted for the heterogeneity of the effect more so than the drug itself (Paton et al, 2007). Both meta-analyses concluded that duration of at least 10 weeks may be necessary to observe an effect. Interestingly, in a 10-week study of adjunctive sulpiride in partial clozapine responders, there was also a significant benefit for positive and negative symptoms (Shiloh et al, 1997).

In addition to study duration, the observed differences in study outcome may also be because of differences in risperidone dose. Of the three negative studies, only the study by Freudenreich et al (2007) also used a risperidone target dose of $4 \mathrm{mg} /$ day and they found a trend for risperidone to differentially improve PANSS total score and to significantly improve the PANSS disorganization factor score. In the other two studies, the mean dose was $3 \mathrm{mg} /$ day (Honer et al, 2006) and $6 \mathrm{mg} /$ day (Anil Yağcioğlu et al, 2005). Although the dose differences are small, an inverted U-shaped dose-response curve is a possible explanation for the observed differences across the five studies.

Neither the current study nor any of the previous studies address the question of how the observed effects with risperidone would compare with simply increasing the dose of clozapine.

In summary, the approach of augmenting clozapine treatment response through the use of adjunctive agents with greater dopamine antagonism received partial support. In combination with previous studies of adjunctive risperidone and sulpiride (Shiloh et al, 1997; Josiassen et al, 2005; Anil Yağcioğlu et al, 2005; Honer et al, 2006; Freudenreich et al, 2007), the current results suggest that this approach may lead to differential and complementary clinical effects, but that benefits may be limited. The clinician confronted with the person who has failed to adequately respond to clozapine may consider the use of adjunctive risperidone. Future studies should evaluate the potential utility of using multiple dopamine-modulating agents with different mechanisms of action, and not just different affinities for the dopamine D2 receptor, in a manner analogous to the use of multiple antiepileptics for treatment-resistant seizure disorders, for people with treatment-resistant schizophrenia who fail to respond to clozapine.

\section{ACKNOWLEDGEMENTS}

The study was supported by the NIMH grant R01 MH4507411, Clozapine Treatment of Schizophrenic Patients (PI: RWB); NIMH grant P30 MH06850, Advanced Center for Intervention and Services Research Grant (PI: RWB); and the University of Maryland General Clinical Research Center grant M01 RR 16500, General Clinical Research Centers Program, National Center for Research Resources, NIH. Double-blind medications were provided by Ortho McNeil Janssen Scientific Affairs, LLC.

\section{DISCLOSURE}

Robert R Conley is a full-time employee and stockholder of Eli Lilly, and this study was completed while he was at the MPRC. James M Gold has been in the advisory boards of Astra-Zeneca and Pfizer, has served as a consultant for Glaxo-Smith-Kline, and has received royalty payments for the Brief Assessment of Cognition in Schizophrenia. Deanna L Kelly has been in the advisory boards of Solvay, Bristol Myers Squibb, and Janssen. Robert W Buchanan has been a DSMB member for Cephalon, Otsuka, and Pfizer; has served as a consultant for Abbott, Cypress Bioscience, GlaxoSmith-Kline, Merck, Organon, Sanofi-Aventis, Solvay, and Wyeth; and has been in the advisory boards of AstraZeneca, Pfizer, and Roche. All the remaining authors have no competing interests or financial support to disclose.

\section{REFERENCES}

Anil Yağcioğlu AE, Kivircik Akdede BB, Turget TI, Tümüklü M, Yazici MK, Alptekin K et al (2005). A double-blind controlled study of adjunctive treatment with risperidone in schizophrenic patients partially responsive to clozapine: efficacy and safety. J Clin Psychopharmacol 66: 63-72.

Awad AG (1993). Subjective response to neuroleptics in schizophrenia. Schizophr Bull 19: 609-618.

Barnes TRE (1989). A rating scale for drug-induced akathisia. $\mathrm{Br} J$ Psychiatry 154: 672-676.

Beaulieu JM, Gainetdinov RR, Caron MG (2007). The Akt-GSK-3 signaling cascade in the actions of dopamine. Trends Pharmacol Sci 28: 166-172.

Benedict R (1997). Brief Visuospatial Memory Test-Revised. Psychological Assessment Resources: Odessa, FL.

Benjamini Y, Hochberg Y (1995). Controlling the false discovery rate: a new and powerful approach to multiple testing. $J R$ Stat Soc, Ser B 57: 1289-1300. 
Benton AL, Hamsher DdeS (1989). Multilingual Aphasia Examination. AJA Associates: Iowa City, IO.

Brandt J (1991). The Hopkins verbal learning test: development of a new verbal memory test with six equivalent forms. Clin Neuropsychol 5: 125-142.

Buchanan RW, Breier A, Kirkpatrick B, Ball P, Carpenter Jr WT (1998). Positive and negative symptom response to clozapine in schizophrenic patients with and without the deficit syndrome. Am J Psychiatry 155: 751-760.

Buchanan RW, Javitt DC, Marder SR, Schooler NR, Gold JM, McMahon RP et al (2007). The cognitive and negative symptoms in schizophrenia trial (CONSIST): the efficacy of glutamatergic agents for negative symptoms and cognitive impairments. Am J Psychiatry 164: 1593-1602.

Cochran SM, McKerchar CE, Morris BJ, Pratt JA (2002). Induction of differential patterns of local cerebral glucose metabolism and immediate-early genes by acute clozapine and haloperidol. Neuropharmacology 43: 394-407.

Conover WJ, Salsburg DS (1988). Locally most powerful tests for detecting treatment effects when only a subset of patients are expected to 'respond' to treatment. Biometrics 44: 189-196.

Cornblatt BA, Keilp JG (1994). Impaired attention, genetics, and the pathophysiology of schizophrenia. Schizophr Bull 20: 31-46.

Correll CU, Rummel-Kluge C, Corves C, Kane JM, Leucht S (2009). Antipsychotic combinations vs monotherapy in schizophrenia: a meta-analysis of randomized controlled trials. Schizophr Bull 35: 443-457.

Feinman RD (2009). Intention-to-treat. What is the question? Nutr Metab 6: 1 .

First MB, Spitzer RL, Gibbon M, Williams J (1997). Structural Clinical Interview for DSM-IV Axis Disorders (SCID-IV). Biometrics Research Department, New York State Psychiatric Institute: New York, NY.

Freudenreich O, Henderson DC, Walsh JP, Culhane MA, Goff DC (2007). Risperidone augmentation for schizophrenia partially responsive to clozapine: a double-blind, placebo-controlled trial. Schizophr Res 92: 90-94.

Gold JM, Carpenter C, Randolph C, Goldberg TE, Weinberger DR (1997). Auditory working memory and Wisconsin Card Sorting Test performance in schizophrenia. Arch Gen Psychiatry 54: $159-165$.

Guy W (1976). ECDEU Assessment Manual for Psychopharmacology. US Department of Health and Human Services publication (ADM) 76-338: Rockville, MD. pp. 534-535.

Hawk AB, Carpenter WT, Strauss JS (1975). Diagnostic criteria and five-year outcome in schizophrenia: a report from the International Pilot Study of Schizophrenia. Arch Gen Psychiatry 32: 343-347.

Heaton RK, Chelune GJ, Talley JL, Kay GG, Curtiss G (1993). Wisconsin Card Sorting Test, Manual. Psychological Assessment Resources: Odessa, FL.

Hershey T, Craft S, Glauser TA, Hale S (1998). Short-term and long-term memory in early temporal lobe dysfunction. Neuropsychology 12: 52-64.

Holcomb HH, Cascella NG, Thaker GK, Medoff DR, Dannals RF, Tamminga CA (1996). Functional sites of neuroleptic drug action in the human brain: PET/FDG studies with and without haloperidol. Am J Psychiatry 153: 41-49.

Honer WG, Thornton AE, Chen EY, Chan RC, Wong JO, Bergmann A, et al, Clozapine and Risperidone Enhancement (CARE) Study Group (2006). Clozapine alone versus clozapine and risperidone with refractory schizophrenia. $N$ Engl J Med 354: 472-482.

Josiassen RC, Ashok J, Kohegyi E, Stokes S, Dadvand M, Paing WW et al (2005). Clozapine augmented with risperidone in the treatment of schizophrenia: a randomized double blind placebo controlled trial. Am J Psychiatry 162: 130-136.

Kane J, Honigfeld G, Singer J, Meltzer H, and the Clozarial Collaborative Study Group (1988). Clozapine for the treatment- resistant schizophrenia: a double-blind comparison with chlorpromazine. Arch Gen Psychiatry 45: 789-796.

Kane JM, Marder SR, Schooler NR, Wirshing WC, Umbricth D, Baker RW et al (2001). Clozapine and haloperidol in moderately refractory schizophrenia: a 6-month randomized and doubleblind comparison. Arch Gen Psychiatry 58: 965-972.

Kapur S, Remington G, Jones C, Wilson A, DaSilva J, Houle S et al (1996). High levels of dopamine D2 receptor occupancy with low-dose haloperidol treatment: a PET study. Am J Psychiatry 153: 948-950.

Kapur S, Zipursky RB, Remington G (1999). Clinical and theoretical implications of 5-HT2 and D2 receptor occupancy of clozapine, risperidone, and olanzapine in schizophrenia. Am J Psychiatry 156: 286-293.

Kivircik Akdede BB, Anil Yağcioğlu AE, Alptekin K, Turgut TI, Tumuklu M, Yazici MK et al (2006). A double-blind study of combination of clozapine with risperidone in patients with schizophrenia: effects on cognition. J Clin Psychiatry 67: 1912-1919.

Kronig MH, Munne RH, Szymanski S, Safferman AZ, Pollack S, Cooper $\mathrm{T}$ et al (1995). Plasma clozapine levels and clinical response for treatment-refractory schizophrenic patients. Am J Psychiatry 152: 179-182.

Lahti AC, Holcomb HH, Weiler MA, Medoff DR, Tamminga CA (2003). Functional effects of antipsychotic drugs: comparing clozapine with haloperidol. Biol Psychiatry 53: 601-608.

Lewis SW, Barnes TR, Davies L, Murrary RM, Dunn G, Hayhurst $\mathrm{KP}$ et al (2006). Randomized controlled trial of effect of prescription of clozapine versus other second-generation antipsychotic drugs in resistant schizophrenia. Schizophr Bull 32: 715-723.

Lezak MD (2004). Neuropsychological Assessment. 4th edn, Oxford University Press: New York, NY.

Liang KY, Zeger S (1986). Longitudinal data analysis using generalized linear models. Biometrika 73: 13-22.

MacGibbon GA, Lawlor PA, Bravo R, Dragunow M (1994). Clozapine and haloperidol produce a differential pattern of immediate early gene expression in rat caudate-putamen, nucleus accumbens, lateral septum and islands of Calleja. Brain Res Mol Brain Res 23: 21-32.

Mantel N (1963). Chi-square tests with one degree of freedom: extensions of the Mantel-Haenszel procedure. J Am Stat Assoc 58: $690-700$.

Masri B, Salahpour A, Didriksen M, Ghisi V, Beaulieu JM, Gainetdinov RR et al (2008). Antagonism of dopamine D2 receptor/ $\beta$-arrestin 2 interaction is a common property of clinically effective antipsychotics. Proc Natl Acad Sci USA 105: 13656-13661.

Matthews C, Klove H (1964). Instruction Manual for the Adult Neuropsychological Battery. University of Wisconsin Medical School: Madison, WI.

McEvoy JP, Lieberman JA, Stroup TS, Dvais SM (2006). Effectiveness of clozapine versus olanzapine, quetiapine, and risperidone in patients with chronic schizophrenia who did not respond to prior atypical antipsychotic treatment. Am J Psychiatry 163: 600-610.

McMahon RP, Arndt S, Conley RR (2005). More powerful twosample tests for differences in repeated measures of adverse effects in psychiatric trials when only some patients may be at risk. Stat Med 24: 11-21.

McMahon RP, Kelly DL, Boggs DL, Li L, Hu Q, Davis JM et al (2008). Feasibility of reducing the duration of placebo-controlled trials in schizophrenia research. Schizophr Bull 34: 292-301.

Nguyen TV, Kosofsky BE, Birnbaum R, Cohen BM, Hyman SE (1992). Differential expression of c-Fos and Zif268 in rat striatum after haloperidol, clozapine, and amphetamine. Proc Natl Acad Sci USA 89: 4270-4274. 
Overall JE, Gorham DR (1962). The brief psychiatric rating scale. Psychol Rep 10: 799-812.

Paton C, Whittington C, Barnes TR (2007). Augmentation with a second antipsychotic in patients with schizophrenia who partially respond to clozapine: a meta-analysis. J Clin Psychopharmacol 27: 198-204.

Pepe MS, Whitaker RC, Seidel K (1999). Estimating and comparing univariate associations with application to the prediction of adult obesity. Stat Med 18: 163-173.

Perry PJ, Miller DD, Arndt SV, Cadoret RJ (1991). Clozapine and nonclozapine plasma concentrations and clinical response of treatment-refractory schizophrenic patients. Am J Psychiatry 148: 231-235.
Reitan RM (1958). Validity of the trail-making test as an indication of organic brain damage. Percept Mot Skills 8: 271-276.

Rosenheck R, Cramer J, Xu W, Thomas J, Henderson W, Frisman L et al (1998). A comparison of clozapine and haloperidol in hospitalized patients with refractory schizophrenia. Department of Veterans Affairs Cooperative Study Group on Clozapine in Refractory Schizophrenia. N Engl J Med 337: 809-815.

Shiloh R, Zemishlany Z, Aizenberg D, Radwan M, Schwartz B, Dorfman-Etrog $P$ et al (1997). Sulpiride augmentation in people with schizophrenia partially responsive to clozapine. A doubleblind, placebo-controlled study. Br J Psychiatry 171: 569-573.

Simpson GM, Angus JWS (1970). A rating scale for extrapyramidal side effects. Acta Psychiatr Scand 212: 11-19. 